\title{
ESTRATÉGIAS ATIVAS DE APRENDIZAGEM E O DESENVOLVIMENTO DE COMPETÊNCIAS TÉCNICAS E ATITUDINAIS
}

ACTIVE LEARNING STRATEGIES AND THE DEVELOPMENT OF TECHNICAL AND ATTITUDINAL COMPETENCES

\section{OLIVEIRA, Michele Cristina Souza Achcar Colla de ${ }^{1}$; JUNQUEIRA, José Roberto}

Almeida $^{2}$; FURLANETTO, Patricia Gomes ${ }^{3}$; CARVALHO, Ana Flávia de ${ }^{4}$

${ }^{1}$ Coordenadora de Operações Acadêmicas no UNIFEOB; ${ }^{2}$ Pró-Reitor Acadêmico no UNIFEOB; ${ }^{3}$ Procuradora Institucional e Coordenadora do Curso de Pedagogia no UNIFEOB;

${ }^{4}$ Diretora Acadêmica no UNIFEOB michele.oliveira@unifeob.edu.br

RESUMO. As estratégias e metodologias ativas de aprendizagem instrução entre pares (Peer Instruction), Sala de aula invertida (Flipped Classroom), Estudo de Caso e Aprendizagem baseada em Projetos (PBL) serão abordadas neste artigo como recursos para a operacionalização do projeto pedagógico institucional do UNIFEOB, que está baseado no desenvolvimento de competências técnicas e atitudinais. A arquitetura dos cursos de graduação parte da identificação das competências - concebido como um conjunto articulado de conhecimentos, habilidades e atitudes - presentes nas diretrizes curriculares nacionais, nas normativas dos órgãos de classe e nas demandas do mercado de trabalho; alinhando os perfis dos ingressantes e dos egressantes ao desenvolvimento de competências técnicas e atitudinais. Em cada curso, em termos de sistematização, parte-se para a distribuição das competências técnicas e atitudinais entre os módulos, os quais são calibrados com a articulação dos domínios cognitivos previstos na taxonomia de Bloom e que permitem a construção de objetivos de aprendizagem compatíveis com a proposta pedagógica e o desenvolvimento de competências técnicas e atitudinais. Nesse sentido, as atividades acadêmicas, nos diversos espaços de aprendizagem, permitem que a teoria e a prática (práxis), sejam aplicadas e vivenciadas pelos docentes e discentes por meio de metodologias e estratégias ativas de aprendizagem que proporcionem a integração dos saberes, a autonomia dos estudantes e o protagonismo dos estudantes, alinhadas às demandas profissionais, pessoais e sociais.

Palavras-chave: estratégias ativas, metodologias, competência.

ABSTRACT. The strategies and active methodologies of Peer Instruction, Flipped Classroom, Case Study and Project Based Learning (PBL) will be approached in this article as resources for the operationalization of the institutional pedagogical project of UNIFEOB, which is based on the development of technical and attitudinal skills. The architecture of undergraduate courses is based on the identification of competences - conceived as an articulated set of knowledge, skills and attitudes - present in the national curricular guidelines, in the norms of the class organs and in the demands of the labor market; aligning the profiles of the newcomers and the evaders to the development of technical and attitudinal competences. In each course, in terms of systematization, we start with the distribution of technical and attitudinal competences between the modules, which are calibrated with the articulation of the cognitive domains provided in the Bloom taxonomy and that allow the construction of learning objectives compatible with the pedagogical proposal and the development of technical and attitudinal competences. In this sense, academic activities in the various teaching-learning spaces allow 


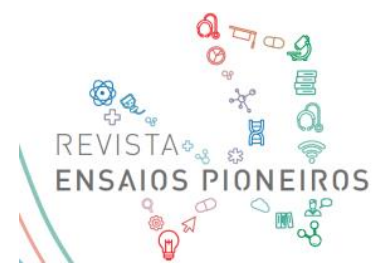

http://ensaiospioneiros.usf.edu.br

theory and practice (praxis) to be applied and experienced by teachers and students through active learning methodologies and strategies that provide the integration of knowledge, the autonomy of the students and the protagonism of the students, aligned with professional, professional and social demands.

Keywords: active strategies, methodologies, competence.

\section{INTRODUÇÃO}

O projeto pedagógico institucional (PPI) do Centro Universitário Fundação de Ensino Octávio Bastos (UNIFEOB) fundamenta-se no desenvolvimento de competências e foi concebido e sistematizado em três grandes eixos, quais sejam: competências específicas ou técnicas, competências atitudinais e as competências para a vida; os quais são permeados por princípios, valores e pelo cumprimento da missão institucional e integrados pelas metodologias e estratégias ativas de aprendizagem com foco no desenvolvimento e aprimoramento de competências que evidenciam, já durante os primeiros períodos de cada curso de graduação, a marca do estudante UNIFEOB - habilitado, comprometido e motivado - e contribuem para a formação integral dos egressos dos cursos da IES.

O compromisso do UNIFEOB em formar profissionais de excelência, com altos níveis de empregabilidade, são um dos pilares dos projetos pedagógicos dos cursos do UNIFEOB, os quais são construídos a partir da formação por competências, ou seja, em cada encontro de aprendizagem, além das competências técnicas específicas do curso, são desenvolvidos e aprimorados em seus estudantes as competências atitudinais necessários ao profissional do século XXI e atualizadas constantemente e revisadas em 2017, quais sejam: flexibilidade, comprometimento, relacionamento interpessoal, trabalho em equipe, comunicação, visão sistêmica, liderança, tomada de decisão e organização e planejamento; cada uma com quatro evidências de posse da competência.

A abordagem deste artigo considera as premissas básicas de um modelo educacional fundamentado no desenvolvimento de competências, no qual o estudante é o protagonista dos processos de aprendizagem, desenvolve a autonomia e interage em ambientes de aprendizagem virtuais e físicos. Para garantir que as premissas básicas sejam alcançadas, recebe especial atenção no planejamento de um curso, Unidades de Estudo (disciplinas) e módulo: a escolha dos temas, a escolha das atividades de desenvolvimento e avaliação; e, em especial, das estratégias e metodologias ativas que serão empregadas para o desenvolvimento de competências técnicas e atitudinais.

A integração dos três eixos de formação é realizada pelo desenvolvimento transversal de competências socioemocionais essenciais para o atuações pessoais e profissionais plenas inteligência emocional, demonstrar empatia, alcançar objetivos e manter relações positivas, entre outras, - alinhado às metodologias e estratégias ativas de aprendizagem, destacando-se a realização em cada um dos módulos de projetos integrados.

Para garantir a constante motivação do estudante, esse passo deve ser seguido continuamente, ao longo do semestre, pelo colegiado de professores de forma participativa e integrativa, garantindo que o planejamento seja cumprido e os objetivos de aprendizagem bem executados. Além disso, deve-se garantir a diversidade de situações e atividades de aprendizagem em harmonização com os conteúdos técnicos, sempre articuladas com as competências em construção e/ou desenvolvimento.

Com base nesses preceitos e no conceito de competências - conjunto articulado de 
conhecimento, habilidade e atitudes, conforme PARRY (1996) - são construídas as estruturas curriculares e planejadas as atividades das unidades de estudo que compõem cada curso; tendo, porém, todos eles, por objetivo que o egresso tenha desenvolvido competências essenciais para o desempenho profissional, acadêmico e pessoal.

Assim, a opção institucional por um projeto pedagógico de desenvolvimento de competências que alinha teoria e prática e proporciona o desenvolvimento de competências técnicas e atitudinais em seus estudantes, orienta o processo de aprendizagem para o desempenho profissional e para a vida, uma vez que a composição das habilidades e competências desenvolvidas em nossos estudantes, o preparam enquanto pessoa, profissional e cidadão por meio da observação sistemática pelos docentes das evidências pré-definidas para cada competência atitudinal, com a realização de feedbacks formativos individuais para cada estudante, ao final de cada bimestre.

As atividades são elaboradas e desenvolvidas a partir de metodologias e estratégias ativas de aprendizagem que permitam o desenvolvimento de competências técnicas e atitudinais; elas devem contextualizar e problematizar os temas a serem trabalhados de maneira prática, tendo como estratégias, entre outras, debates, seminários, aulas expositivas dialogadas, simulações de procedimentos, discussões sobre filmes e obras literárias, leituras direcionadas; visitas técnicas, estudos de casos, a partir do objetivo primário: integrar os temas e competências desenvolvidos nas outras Unidades de Estudo, que compõem o módulo, e são orientados para o desenvolvimento do Projeto Integrado.

Neste artigo, abordaremos as estratégias ativas de aprendizagem instrução entre pares (Peer Instruction), Sala de aula invertida (Flipped Classroom), Estudo de Caso e Aprendizagem baseada em Projetos (PBL) com enfoque no desenvolvimento de competências técnicas e atitudinais. Por convenção institucional, adota-se como metodologias, tão somente: Estudo de Caso, Contextualização e Problematização.

Em constante aprimoramento das práticas de aprendizagem que promovam o desenvolvimento ou aprimoramento de competências técnicas e atitudinais, destacam-se entre os recursos a utilização das Tecnologias da informação e comunicação (TICs), uma vez que, inseridos na sociedade do conhecimento e da informação, docentes e discentes podem manter, através das delas, contato direto e instantâneo, formar uma rede colaborativa de atividades em equipes, independentemente de onde os estudantes e os professores estejam, tornando a aprendizagem mais significativa, flexível e perene.

A comunicação instantânea com os discentes, a utilização do Ambiente Virtual de Aprendizagem (AVA), Classroom (Google for education), a rede social Facebook, entre outros ambientes colaborativos e participativos para as propiciam o desenvolvimento de competências e as discussões dos temas abordados em sala de aula, a postagem de materiais e a realização de fóruns, curadoria ou indicações de vídeos disponíveis no YouTube ou mesmo no Ambiente Virtual de Aprendizagem aproximam os conhecimentos acadêmicos à interação social que os discentes desenvolvem junto às redes sociais, em sintonia com a moderna tendência da aprendizagem direcionada a identificar e suprir as necessidades formativas de cada estudante.

Nesse contexto de aprendizagem, as estratégias ativas ou inovadoras, na perspectiva do desenvolvimento por competências e do projeto pedagógico institucional do UNIFEOB: “(...) visam à consecução de objetivos, portanto, há que ter clareza sobre aonde se pretende chegar naquele momento com o processo de aprendizagem" (ANASTASIOU e ALVES, 2012).

Utilizando como suporte as estratégias de aprendizagem - aprendizagem baseada em problemas ou projetos, aprendizagem em times, interação entre pares, sala de aula invertida, entre outras - aplicam-se ou exploram-se meios, os modos, maneiras e formas de se evidenciar 
o pensamento do estudante e o desenvolvimento das competências técnicas atitudinais.

As estratégias ativas devem estar vinculadas ao projeto pedagógico institucional, aos objetivos e temas propostos e devem fazer sentido no contexto da aprendizagem do estudante. A estratégia ativa isolada do contexto do projeto pedagógico não faz sentido e sim traz a sensação de desconexão é fazer por fazer.

\section{ESTRATÉgIAS ATIVAS DE APRENDIZAGEM, TAXONOMIA DE BLOOM E OBJETIVOS DE APRENDIZAGEM}

A organização do plano pedagógico de unidade de estudo, na perspectiva das competências e habilidades específicas do módulo, para FERRAZ e BELHOT ${ }^{[1]}$, "Essa estruturação é resultado de um processo de planejamento que está diretamente relacionado à escolha dos conteúdos, de procedimentos, de atividades, de recursos disponíveis, de estratégias ativas, de instrumentos de avaliação e da metodologia a ser adotada por um determinado período de tempo".

Nesse sentido, objetivando alinhar as competências técnicas e atitudinais indica-se, em síntese, os elementos do domínio cognitivo identificados na taxonomia de BLOOM, que originalmente elenca seis grandes comandos verbais: CONHECER, COMPREENDER, APLICAR, ANALISAR, AVALIAR e CRIAR.

Entende-se que o estudante "CONHECER" quando é capaz ou detém a habilidade de recordar ou reconhecer informações, ideias e princípios na forma em que foram aprendidos. Exemplificando a conceituação através de verbos, quando o estudante anota, defini, reconhece, rotula, seleciona, interage em redes sociais com base em determinado conceito, podemos afirmar que ele o conhece.

Em relação à “COMPREENDER” exemplifica-se que o estudante traduz e interpreta a informação com base em um conhecimento prévio.

Adentrando o terceiro nível do domínio cognitivo proposto por BLOOM, temos o verbo “APLICAR", nessa etapa de domínio do conteúdo específico, o estudante seleciona, transfere e se utiliza de dados, conceitos e princípios para completar um problema e/ou tarefa, com um mínimo de supervisão. E detém as habilidades de desenvolver, empregar, encontrar, ajustar, apreciar e interpretar, compartilhar em redes e editar.

Quanto ao quarto nível do domínio cognitivo proposto por BLOOM, quando o estudante distingue, organiza e relaciona pressupostos, hipóteses, evidências ou estruturas de uma questão ou declaração entende-se que detém as habilidades necessárias para "ANALISAR", cujos verbos sinônimos são: apresentar, associar, avaliar, calcular, considerar, constatar, criticar, debate, dividir, experimentar, identificar, ilustrar, inspecionar, perguntar, reconhecer, entre outros.

No quinto nível proposto temos o verbo "AVALIAR”, nesse contexto de aprendizagem o estudante aprecia, avaliar ou critica baseado em padrões e em critérios específicos. $\mathrm{O}$ estudante que desenvolve atividades baseadas neste nível de cognição possui habilidades de argumentar, categorizar, criticar, decidir, defender, determinar, escolher, explicar, fundamentar, interpretar, resolver, validar, valorizar, entre outros.

Por fim, e não menos importante, o estudante está apto a "CRIAR" quando integra e conjuga ideias em um produto, projeto ou proposta novos para ele e está preparado para inventar, manejar, obter, organizar, planificar, projetar, relatar, transmitir, entre outras ações. Para FERRAZ e BELHOT (2016) é “(...) um dos instrumentos existentes que pode vir a facilitar esse processo nos cursos superiores é a taxonomia proposta por Bloom et al. (1956), que tem, 
explicitamente, como objetivo ajudar no planejamento, organização e controle dos objetivos de aprendizagem".

Nesse sentido, destaca-se a importância da delimitação do OBJETIVO DE APRENDIZAGEM, que é produto da reflexão sobre as habilidades, competências atitudinais e conhecimentos técnicos que esperamos que os nossos estudantes tenham aprendido ao final de nosso programa educacional, para tanto, o currículo acadêmico da UNIFEOB é estruturado para o desenvolvimento de competências técnicas e atitudinais.

Em conjunto, visando alinhar os objetivos de aprendizagem com o perfil do estudante de graduação as formas de aprendizagem significativa destacam-se, pois ocorre quando as informações, conceitos e/ou definições são relacionados a um aspecto relevante, que desperte a curiosidade do estudante e promova o desenvolvimento de competências específicas e atitudinais.

$\mathrm{Na}$ perspectiva do Estudante objetiva-se com a aprendizagem significativa: o desenvolvimento de competências técnicas, atitudinais, a promoção de atividades de pesquisas, intercâmbios de ideias e a construção e compartimento do conhecimento, propiciando o desenvolvimento integral do estudante.

Neste sentido BACICH (2018): “As pesquisas atuais da neurociência comprovam que o processo de aprendizagem é único e diferente para cada ser humano, e que cada pessoa aprende o que é mais relevante e o que faz sentido para si, o que gera conexões cognitivas e emocionais".

Na concepção das competências e as habilidades específicas da Unidade de Estudo devemos nos atentar para a redação de:

a. Competências e habilidades específicos claramente derivados das competências e habilidades gerais;

b. Descrição de comportamentos e produtos (fazer e realizar) capturáveis através de tarefas/atividades;

c. Contém verbos de ação delimitando e especificando comportamentos observáveis;

d. Redação clara, objetiva e direta;

As relações que se estabelecem entre o desenvolvimento de competências, a taxonomia de Bloom e a estratégias ativas confluem para a aprendizagem em espiral (BACICH, 2018), partindo de níveis mais simples para os mais complexos de conhecimentos, habilidades e atitudes nas diversas dimensões da vida; os quais são contemplados nos três grandes eixos do PPI do UNIFEOB.

\section{METODOLOGIA}

As metodologias e estratégias abordadas neste artigo foram objeto da capacitação docente realizada em janeiro de 2016 e 2017 durante os Simpósios de Desenvolvimento Profissional de Docentes, iniciando oficialmente o planejamento acadêmico dos anos letivos e intensificando as ações institucionais de capacitação docente e de consolidação do Projeto de Formação por Competências, apresentando diversas ferramentas pedagógicas e didáticas.

Alinhado ao projeto pedagógico institucional, as metodologias devem ser ferramentas à disposição do docente. Para isso, o docente deve entender quais os objetivos propostos durante o planejamento e deve saber utilizar corretamente as metodologias e estratégias adequadas. Visando a correta utilização e buscando alcançar os melhores resultados, a capacitação docente é fundamental para o perfeito desenvolvimento do Projeto. 
Para MORIN apud BACICH (2018), "Aprendemos o que nos interessa, o que encontra ressonância íntima, o que está próximo do estágio de desenvolvimento em que nos encontramos. Dewey (1950), Freire (1996), Ausubel et al. (1980), Rogers (1973), Piaget (2006), Vygotsky (1998) e Bruner (1976), entre tantos outros e de forma diferente, têm mostrado como cada pessoa" (BACICH, 2018).

Alinhar o desenvolvimento de competências técnicas e atitudinais, com conteúdos significativos e que promovam o protagonismo e a autonomia do estudante, demandam dos docentes planejamento e encontros de aprendizagem diferenciados e que promovam a eficiente interação entre teoria e prática.

Neste sentido, as estratégias ativas de aprendizagem são ferramentas essenciais para a operacionalização do projeto pedagógico institucional. Passaremos a descrever as estratégias instrução entre pares (Peer Instruction), Sala de aula invertida (Flipped Classroom), Estudo de Caso e Aprendizagem baseada em Projetos (PBL) que foram apresentadas ao corpo docente da UNIFEOB nos anos de 2016 e 2017, por meio de oficinas de aprendizagem.

\section{INSTRUÇÃO ENTRE PARES (PEER INSTRUCTION)}

A estratégia ativa Peer Instruction em tradução livre, "instrução entre pares", pode ser concebido como o entendimento, as discussões e aplicabilidade dos conceitos, utilizando-se a interação entre os estudantes organizados em duplas aleatórias - ou previamente definidas pelo docente.

A estratégia original é produto dos estudos de Eric Mazur, professor do Departamento de Física de Harvad, neste artigo apresenta-se uma nova abordagem de utilização, adequada às nossas características educacionais e ao perfil de nossos estudantes. Deve-se estimular o estudante a realizar as atividades pré-aula (leituras de textos, realização prévia de exercícios, entre outros) e a participar ativamente das discussões com os pares e com o mediador (docente ou tutor).

A proposta de aplicação desta estratégia inovadora ativa é pautada pela busca da simplicidade de procedimentos preparatórios, bem como os de execução, tais como:

TEMA GERADOR: escolha alinhada aos principais conteúdos do módulo.

Para a implementação da estratégia "peer instruction" em sala, pode-se adotar a sequência a seguir descrita:

1. Escolha do texto para leitura pré-aula (sugere-se, no máximo, 02 laudas) e elaboração do Cronograma de atividades do Encontro. Antes da distribuição dos textos e da formação das duplas deve-se informar aos estudantes quais competências técnicas e atitudinais serão desenvolvidas e quais as evidências o professor irá observar.

2. Concessão de tempo para leitura individual do texto em sala (30 minutos).

3. Organização em duplas.

4. Na sequência o Docente promoverá a conceituação, problematização ou apresentação do Caso a ser debatido.

5. Os estudantes devem receber as questões dissertativas e/ou testes para a resolução em duplas. Discussões em duplas.

6. Devolutiva/Feedback para as duplas ao final do encontro de aprendizagem. 


\section{PROPOSTA HÍBRIDA: INÍCIO NO AMBIENTE VIRTUAL DE APRENDIZAGEM E FINALIZAÇÃO EM SALA DE AULA}

\section{Tema Gerador: X}

Para a implementação da estratégia "peer instruction" em AVA, pode-se adotar a sequência a seguir descrita:

1. Escolha do texto para leitura pré-aula (sugere-se 02 laudas) e elaboração do Cronograma de atividades do Encontro.

2. Quais competências técnicas e atitudinais pretendo desenvolver nos estudantes?

3. O texto deve ser disponilizado no AVA com uma semana de antecedência do encontro de aprendizagem.

4. Preparação das questões pré-aula, com base no texto indicado.

5. As questões pré-aula devem ser disponibilizadas dois dias antes do encontro de aprendizagem. Sugere-se a utilização de um formulário do Google Drive para colhimento das respostas.

6. Extração das resoluções do formulário do Google Drive. Com essa ferramenta, os docentes podem mensurar o grau de acerto e de assimilação dos conteúdos/conceitos.

7. Contextualização/exposição dos temas em sala de aula. E resolução em sala das questões pré-aula.

8. Com base na análise das respostas das questões pré-aula, o docente está apto a aprofundar os pontos de dúvidas dos estudantes.

9. Resoluções de novas questões durante a aula.

10. Discussões em duplas.

11. Devolutiva/Feedback ao final do encontro de aprendizagem.

\section{Sala de Aula Invertida (Flipped Classroom)}

A estratégia inovadora denominada sala de aula invertida é, em síntese, a inversão do cronograma e da realização de atividades de uma sala de aula ou espaço de aprendizagem. E pressupõe que a exposição não seja feita no encontro presencial, ocasião em que os estudantes participarão de: Projetos; Resoluções de exercícios em pares; Elaboração de seminários/mesas redondas; Mapas conceituais; Portfólios, entre outras estratégias de aprendizagem.

Para MORIN apud BACICH (2018), a sala de aula invertida:

“(...) é uma estratégia ativa e um modelo híbrido, que otimiza o tempo da aprendizagem e do professor. O conhecimento básico fica a cargo do estudante - com curadoria do professor - e os estágios mais avançados têm interferência do professor e também um forte componente grupal. Bergmann e Sams (2016) foram os primeiros divulgadores de algumas técnicas da aula invertida, principalmente utilizando o vídeo como material para estudo prévio, com a vantagem de que cada estudante pode assistilo no seu ritmo, quantas vezes precisar e solicitando, se necessário, a colaboração dos pais ou colegas. Depois o professor pode orientar atividades de acordo com a situação de cada estudante e suas necessidades específicas" (BACICH, 2018).

As principais ferramentas utilizadas para a aplicação da estratégia são: apresentação de vídeos gravados em Power Point; Gravação de vídeo com o celular; Indicação de texto: 
leitura dirigida/guia de orientação; e a indicação de vídeos (por exemplo, links do Youtube) associados a uma atividade dirigida/guia de orientação.

\section{PROPOSTA}

\section{TEMA GERADOR: $X$}

Para a implementação da estratégia "sala de aula invertida", pode-se adotar a sequência a seguir descrita:

\section{Planejamento e organização da leitura pré-aula:}

1. Seleção de texto curtos e com leitura direcionada;

2. Indicações de vídeos e/ou filmes.

\section{Planejamento e organização do encontro presencial:}

1. Iniciar o encontro de aprendizagem presencial através do material disponibilizado no AVA;

- Objetivo: atribuir maior significado a estratégia sala de aula invertida.

2. Finalizar o encontro presencial indicando se no próximo haverá sala de aula invertida;

3. A sala de aula invertida não é indicada para todos os encontros e temas;

\section{ESTUDO DE CASO}

A utilização da metodologia do estudo de caso, na perspectiva do desenvolvimento de competências, é de extrema importância para o estímulo à autonomia intelectual do estudante e de seu protagonismo, uma vez que se baseia na aplicação da teoria a situações práticas a partir da problematização de casos reais ou hipotéticos.

A metodologia do estudo de caso proporciona ao docente uma gama de possibilidade de abordagem de conteúdo de modo a atingir os mais diversos públicos, ou seja, a partir de diversas abordagens da mesma temática possibilita-se ao estudante aprofundar seus conhecimentos, com base em aprendizagem híbrida e customizável.

Nesse sentido, os estudos de casos no ensino superior por intermédio das estratégias ativas Peer Instruction, Team-Based Learning Learning e Writing Across the Curriculum (WAC), embasa-se na multidisciplinaridade e na transdisciplinaridade, tendo o escopo de formar profissionais com visão holística, através do desenvolvimento das competências atitudinais eleitas pela UNIFEOB.

Segundo C. Roland Christensen Center for Teaching and Learning, Harvard Business School, a metodologia ativa "Case Study" ou Estudo de caso estrutura-se em: condições prévias, procedimentos e resultados, os quais estão descritos a seguir:

1. Condições prévias:

a) Respeito mútuo entre professor e estudantes e também entre os próprios estudantes.

b) Professor e estudantes vão para a aula muito bem preparados.

c) Professor e estudantes usam critérios rigorosos e estão dispostos a correr riscos e considerar diferentes pontos de vista.

O caso, os materiais de apoio e a avaliação são articulados ao plano de ensino e parte da estrutura eficaz de um módulo ou curso. 
2. Procedimentos: a aula começa e termina no tempo determinado e o Professor:

a) Prepara o conteúdo e o processo, incluindo um conjunto claro de objetivos de aprendizagem, um plano de bordo, uma questão de abertura, aprofundamento de discussão, transições, perguntas de acompanhamento e comentários finais.

b) Escuta atenta durante todo o debate em classe.

c) Gerencia ativamente fluxo e a estrutura da classe e, ao mesmo tempo, responde com flexibilidade aos comentários dos estudantes.

d) Coloca questões desafiadoras, convida estudantes a responderem (de modo prédeterminado ou aleatório) para acompanhar e promover a discussão de alta qualidade em classe.

e) Estimula discussão reflexiva estudante-estudante e incentiva a participação do maior número possível de estudantes.

f) Fornece aos estudantes as condições para que sustentem as discussões em classe.

g) Encerra o caso de modo apropriado, a fim de promover o prosseguimento das discussões, das aulas, cursos e módulos seguintes.

3. Resultados:

a) A aprendizagem em sala de aula excede substancialmente a aprendizagem préclasse e, ainda, estimula o aprendizado depois da aula.

b) O aprendizado ultrapassa os limites de uma única disciplina ou curso, tornando-se muito mais profundo uma vez que promove a ligação entre disciplinas, módulos e cursos.

c) Os estudantes se envolvem porque são energizados e desafiados pelas discussões em classe.

d) Estudantes descobrem, articulam e desenvolvem a maioria das visões críticas, mesmo com o professor sempre na liderança do processo.

Assim, os estudantes ao serem submetidos a essa modalidade de aprendizagem devem:

a) Participar e ouvir ativamente ao longo das discussões em classe.

b) Contribuir com ideias, análises e experiências pessoais, em vez de simplesmente apresentar os fatos do caso.

c) Construir a partir de comentários e críticas dos outros, além de debater diferentes pontos de vista.

\section{APRENDIZAGEM BASEADA EM PROJETOS (PBL)}

PBL é a sigla em inglês para Project Based Learning, ou seja, Aprendizagem baseada em Projetos, as quais são estratégias ativas de aprendizagem focadas no trabalho colaborativo, na autonomia do estudante e no desenvolvimento de competências técnicas e atitudinais.

O PBL (Aprendizado Baseado em Projetos) é um método de aprendizado centrado no estudante, tem o problema com elemento motivador do estudo e integrador do conhecimento, habilidades e atitudes.

Os Projetos dos Módulos/Projetos Integrados devem ser exemplos autênticos do tipo de problema que os estudantes irão enfrentar no mercado de trabalho: a questão principal, ou seja, questão motivadora das atividades!

1) Deve ser inspiradora, explícita e clara: efetividade do contrato pedagógico.

2) Quais as competências específicas? Quais as evidências das competências 
atitudinais?

3) Deve envolver aspectos que despertem a curiosidade e o interesse dos Estudantes.

4) Estratégia que deve envolver todas as Unidades de Estudos;

5) Projeto deve ser debatido e discutido com os Estudantes;

Nas capacitações docentes realizadas, foram apresentados ao corpo docente as seguintes etapas para o planejamento com base no PBL:

$\left.1^{\circ}\right)$ Definição do tema gerador do Projeto Integrado, em sintonia com o(s) eixo(s) temático(s) do Módulo;

$2^{\circ}$ ) Quais conteúdos de cada Unidade de Estudo serão trabalhos para compor o Projeto Integrado (Produto do Módulo)?

$\left.3^{\circ}\right)$ Em que momento do módulo esses conteúdos serão necessários? O processo de identificação dos materiais, recursos e das contribuições de cada unidade de estudo para o projeto é essencial. Facilitando o estabelecimento dos relacionamentos entre as atividades do projeto e as unidades de estudo do módulo. Integrado.

$4^{\circ}$ ) Definir e declarar quais competências serão desenvolvidas e os objetivos do Projeto

$\left.5^{\circ}\right)$ Planejar o gerenciamento do cronograma: estabelecer os procedimentos e a documentação (materiais e recursos) para o planejamento, desenvolvimento, gestão, gerenciamento, execução e controle do cronograma do projeto.

$\left.6^{\circ}\right)$ Definir e sequenciar as atividades de cada Unidade de Estudo na construção do Projeto: O processo de identificação e a documentação das ações específicas a serem realizadas para a elaboração da socialização acadêmica ou produto (resultado).

$7^{\circ}$ ) Estimar os recursos das atividades: estimativa dos tipos, quantidades e qualidades dos materiais/insumos, recursos humanos, equipamentos ou suprimentos que serão necessários para realizar cada encontro de aprendizagem.

$8^{\circ}$ ) Estimar as durações das atividades: estimativa do número de períodos que serão necessários para terminar atividades específicas com os recursos estimados.

$9^{\circ}$ ) Desenvolver o cronograma: análise das sequências das atividades, suas durações, recursos necessários e restrições do cronograma visando criar o modelo do cronograma do projeto.

$10^{\circ}$ ) Forma de apresentação do Projeto para os estudantes: desafiador, mensurável, significativo e que promova o desenvolvimento efetivo de competências atitudinais e técnicas/específicas.

\section{RESULTADOS E DISCUSSÃO}

O presente artigo é produto dos estudos, reflexões e das práticas implementadas para as capacitações docentes realizadas no UNIFEOB no ano de 2016 e 2017. Sob a perspectiva da aprendizagem significativa, com as oficinas de estratégias ativas de aprendizagem, objetivouse a promoção de atividades que permitam o desenvolvimento de competências técnicas e atitudinais. Promovendo, também, a integração entre os, aproximadamente, 200 docentes do UNIFEOB.

Neste ano, a aprendizagem baseada em projetos destacou-se nas oficinas de estratégias ativas de aprendizagem em razão das diretrizes institucionais para o Projeto Integrado, enquanto componente curricular multidisciplinar, interdisciplinar e transdisciplinar de cunho teórico- 
prático que engloba os temas abordados por todas as unidades cursadas pelo estudante, alinhado ao eixo temático de cada módulo.

Objetivando-se com a iniciativa:

a) Desenvolver nos estudantes a capacidade de aplicação de conceitos e teorias, de forma integrada, proporcionando-lhes a oportunidade de articular as unidades de estudos e os temas estudados com as práticas profissionais, para consolidação de experiências e desempenho de competências técnicas/específicas e atitudinais;

b) Contribuir para o aperfeiçoamento dos estudantes na solução de situaçõesproblemas reais ou hipotéticas, levando em consideração as potencialidades de aplicações práticas e de intervenção na sociedade;

c) Capacitar o estudante para a elaboração e exposição de seus trabalhos por meio de metodologias e estratégias adequadas que permitam a socialização acadêmica: apresentação oral, construção de maquetes; dramatização, publicações acadêmicas, entre outros.

d) Despertar o interesse pela pesquisa como meio para a solução de problemas;

e) Propor projetos de empreendedorismo que permitam a solução de problemas e promovam melhorias contribuam com o projeto de vida de cada estudante.

f) Estimular a construção do conhecimento coletivo, a multidisciplinaridade, interdisciplinaridade e transdisciplinaridade e os processos de inovação.

g) Centralizar as atividades extraclasse do módulo no PI, a fim de manter o equilíbrio das atividades nas Unidades de Estudos.

Os docentes participaram das seguintes oficinas que integraram a aprendizagem baseada em projetos a estratégias ou ferramentas didáticas: Oficina de Aprendizagem Baseada Em Projetos: Estudo De Caso; Oficina de Aprendizagem Baseada Em Projetos: Sala De Aula Invertida e Oficina de Aprendizagem Baseada Em Projetos: Canvas.

Durante os simpósios de capacitações docentes, em sua segunda edição, realiza-se a etapa final do "PROJETO DE PRÁTICAS BEM-SUCEDIDAS EM SALA DE AULA ILZA AGOSTINHO" iniciativa institucional que busca reconhecer, identificar e socializar as práticas docentes que potencializaram a aprendizagem nos anos de 2015 e 2016, dando visibilidade às experiências pedagógicas consideradas exitosas e possíveis de serem compartilhadas entre os docentes da IES. Em especial, estimulou a participação dos docentes como sujeitos ativos na efetiva e permanente implementação do projeto pedagógico institucional de Formação por Competências e os incentivou a desenvolver uma cultura de autoavaliação e de reflexão sobre sua prática acadêmica.

Na perspectiva do projeto pedagógico institucional de Formação por Competências, destaca-se a importância da utilização de estratégias de aprendizagem, que propiciem a junção da teoria e da prática, orientadas para o desenvolvimento de competências, habilidades, atitudes e conhecimentos técnicos. Em suma, o projeto pedagógico institucional (PPI) busca alinhar objetivos de aprendizagem, perfil do estudante de graduação e o desenvolvimento de práticas pedagógicas ativas e eficientes.

Nesse sentido, o "2 PROJETO DE PRÁTICAS BEM-SUCEDIDAS EM SALA DE AULA ILZA AGOSTINHO”, ao propor visibilidade às práticas docentes essenciais ao pleno desenvolvimento do PPI, funcionou como um desafio a todos, tornando-se assunto constante em toda a comunidade acadêmica.

$\mathrm{Na}$ perspectiva do Estudante, objetivou-se, com a aprendizagem significativa, o desenvolvimento de competências específicas e atitudinais, a promoção de atividades de 
pesquisas, intercâmbios de ideias e a construção e compartilhamento do conhecimento produzido.

Em relação à aprendizagem colaborativa, é importante ressaltar que, através da especificidade do projeto pedagógico institucional que traz como questão essencial o desenvolvimento de comportamentos necessários ao profissional do século XXI, as competências como trabalho em equipe, comunicação, comprometimento, adaptabilidade e flexibilidade, responsabilidade social, raciocínio lógico e argumentação, gestão do tempo, liderança, empreendedorismo, criatividade e inovação e visão sistêmica foram ainda mais valorizadas e desenvolvidas através do debate promovido pelas etapas do " $2^{\circ}$ PROJETO DE PRÁTICAS BEM-SUCEDIDAS EM SALA DE AULA ILZA AGOSTINHO”.

Em síntese, esta prática objetivou: reconhecer o trabalho dos professores no exercício da atividade docente; identificar, reconhecer e socializar as práticas que potencializam a aprendizagem; dar visibilidade às experiências pedagógicas conduzidas pelos professores e consideradas exitosas e passíveis de adoção por outros professores da UNIFEOB; estimular a participação dos professores como sujeitos ativos na efetiva e permanente implementação do Projeto Pedagógico Institucional de Formação por Competências da IES e incentivar os docentes a desenvolverem a cultura da autoavaliação e da reflexão sobre sua prática docente.

\section{CONCLUSÃO}

A utilização de estratégias ativas de aprendizagem, alinhadas ao desenvolvimento de competências e aos domínios cognitivos da taxonomia de BLOOM compõem a estrutura operacional do projeto pedagógico institucional do UNIFEOB, cujas valores e princípios refletem os perfis dos ingressantes e dos egressos de cada curso, criando condições para o desenvolvimento integral do estudante.

Conclui-se que as estratégias ativas no processo de aprendizagem colaboram sobremaneira para um aprendizado duradouro e consistente para os estudantes. As estratégias devem estar vinculadas ao projeto pedagógico institucional para que façam sentido e construam o saber, sendo utilizadas como recursos e ferramentas para operacionalização das diretrizes conceituais e de concepção do citado projeto.

O aprendizado através da prática leva ao entendimento, a importância e a utilização do que se aprendeu permanentemente. A construção do aprendizado utilizando situações reais faz com que o estudante se torne ativo e capaz de buscar as soluções e inovações necessárias para o ambiente real de trabalho atual, ou mesmo futuro, no qual não saberemos quais serão as inquietações, problemas ou inovações necessárias para sua resolução. Ensinar como se faz, como se busca e como se soluciona, será o futuro da educação e de excelentes profissionais no mercado de trabalho.

\section{REFERÊNCIAS}

ANASTASIOU, Léa das Graças Camargos; ALVES, Leonir Pessate (Orgs.). Processos de ensinagem na universidade: pressupostos para as estratégias de trabalho em aula. 10 ed. Joinville: UNIVILLE, 2012.

BACICH, Lilian. Metodologias Ativas para uma Educação Inovadora: Uma Abordagem Teórico-Prática. Penso, 2018. [Minha Biblioteca]. 
BAFFI, M. A. T. O planejamento em educação: revisando conceitos para mudar concepções e práticas. In: BELLO, J. L. P. Pedagogia em Foco. Petrópolis. 2002. Disponível em <http://niead.ufac.br/moodle/pluginfile.php/13481/mod_resource/content/1/ Texto\% 20 sobre\%20planejamento.pdf> Acesso em: 14 de jan. de 2016.

BEHRENS, M.A. Formação continuada dos professores e a prática pedagógica. Curitiba: Champagnat, 1996.

BENDER, W. N. Aprendizagem baseada em projetos: educação diferenciada para o século XXI. Porto Alegre: Penso, 2014.

BERBEL, Neusi Aparecida Navas. As metodologias ativas e a promoção da autonomia de estudantes. Semina: Ciências Sociais e Humanas, Londrina, v. 32, n. 1, p. 25-40, jan./jun. 2011.

BERCHIOR, Aparecida do Carmo Frigeri. In Workshop Projeto Pedagógico de Curso: Gestão e Avaliação. GEdcu 2013.

BORDENAVE, Juan Diaz; PEREIRA, Adair Martins. Estratégias de ensino-aprendizagem. 13. ed. Petrópolis: Vozes, 1993.

COLOMBO, Andréa Aparecida; BERBEL, Neusi Aparecida Navas. A Metodologia da Problematização com o Arco de Maguerez e sua relação com os saberes de professores. Semina: Ciências Sociais e Humanas, Londrina, v. 28, n. 2, p. 121-146, jul./dez. 2007.

COMO ESCREVER UM ESTUDO DE CASO. Disponível < http://www.labmi.com.br/wpcontent/uploads/2014/06/Como-escrever-um-estudo-de-caso.pdf>. Acesso em 01 ago. 2015.

CONSELHO FEDERAL DE MEDICINA VETERINÁRIA. Estratégias de ensinoaprendizagem para desenvolvimento das competências humanísticas. Propostas para formar médicos veterinários para um mundo melhor. Disponível em < http://portal.cfmv.gov.br/uploads/files/Estrategias\%20de\%20Ensino-aprendizagem $\% 20$ para\%20Desenvolvimento\%20das\%20Competencias\%20Humanisticas_site.pdf $>$. Acesso em 12 jan. 2016.

DEMO, Pedro. Avaliação Qualitativa. 6.ed. Campinas: Editores Associados, 1999.

ELUF, Luiza Nagib. A paixão no banco dos réus. Editora Saraiva.

FERRAZ, Ana Paula do Carmo Marcheti; BELHOT, Renato Vairo. Taxonomia de Bloom: revisão teórica e apresentação das adequações do instrumento para definição de objetivos instrucionais. Disponível em < http://www.scielo.br/pdf/gp/v17n2/a15v17n2>. Acesso em 12 jan.2016.

FRANCO, Max. Storytelling e suas aplicações no mundo dos negócios. São Paulo: Atlas, 2015. 
GUEDES, Edson Claiton. A reforma universitária segundo a teoria do pensamento complexo de Edgar Morin. Disponível em <http://educere.bruc.com.br/ANAIS2013/pdf/6847_4456.pdf>.

MITRE, Sandra Minardi et al. Metodologias ativas de ensino-aprendizagem na formação profissional em saúde: debates atuais. Ciênc. saúde coletiva [online]. 2008, vol.13, suppl.2, pp. 2133-2144. ISSN 1413-8123. Disponível em <http://dx.doi.org/10.1590/S1413$81232008000900018>$.

MORIN, Edgar. Os sete saberes necessários à educação do futuro. 12. ed. São Paulo, SP; Brasília, DF: Cortez: UNESCO, 2007.

MORIN, Edgar; ALMEIDA, Maria da Conceição; CARVALHO, Edgard de Assis (org.). Educação e complexidade: os sete saberes e outros ensaios. 5. ed. São Paulo, SP: Cortez, 2009.

PARRY, Scott. B. - The quest for competencies - Training, julho 1996, p. 48-54; REINHOLD, Helga Hinkenickel; LIMA, Regina Célia de Carvalho Paschoal. Manual UNIFEOB Para Trabalhos Acadêmicos, 2014.

ROCHA, Eduardo Peixoto. In Painel: Currículo por Competências. GEdcu 2015.

SCALLON, Gérard. Avaliação da aprendizagem numa abordagem por competências. Tradução de Juliana Vermelho Martins. Curitiba: PUCPRess, 2015. 